\title{
THE 'KNOWLEDGE SOCIETY': A GLIMPSE INSIDE THE MINDS OF MANAGEMENT STUDENTS
}

\author{
Angela Mead \\ University of Waikato \\ Hamilton
}

\begin{abstract}
This paper focuses on the 'knowledge society' in New Zealand. It holds that the use of the term is unclear. It identifies two dominant themes in the literature: the 'knowledge society' as embedded in 'Third Way' thinking, and the 'knowledge society' as a positive response to a changing society. This paper reports on a qualitative study of the views of a small group of final year BMS students about the 'knowledge society'. The respondents had come to university directly from school. The research consisted of three one hour, semi structured, taped interviews. Three themes emerged: "Knowledge will get me the things I want;" "I need current global knowledge to survive out there;" and "I resent the current government'." The findings support the literature in that the respondents acknowledge that globalisation and technology are key drivers of a changing society. They also challenge the literature in that respondents do not have a clear understanding of the concept. The respondents strongly associate market use-fullness to knowledge. The paper suggests that a 'New Right-Third Way' dichotomy still exists. The paper also presents an insight into the 'optimism' and 'individualism' embedded in the respondents' comments. Perhaps this diversity of knowledge should be celebrated and used to empower the whole of society.
\end{abstract}

\section{Introduction}

Whilst sorting through piles of literature one day, I started to question the clearly different schools of thought that are inherently embedded within one educational institution, which prescribes and facilitates the growth of knowledge 'The University'. This thought urged me to seek more insight in to popular views of particular groups about our 'knowledge society'. I was astounded when talking to a group of acquaintances, the different pockets of knowledge that existed, particularly in relation to New Zealand and our society. I set out to read current literature around the topic and was further astonished to find the 'knowledge society' is a difficult term to pin down. Questions of concern began to emerge in my mind about the complexity of this issue to society.

New Zealand is intrinsically linked to the global market, which in turn changes the way society functions. Education has been identified by the government as a 'way forward', a coping mechanism to survive. The purpose of this paper is to examine the 'knowledge society' in New Zealand. A literature review is first provided to identify the core themes in respect to a 'knowledge society'. I then provide a brief critique of the literature, which presents the key limitations and weaknesses. Following the literature review, the research design and selected findings are presented, which will then be wrapped up in a discussion containing key elements of the findings. I conclude with new directions for knowledge and our understanding of it in a contemporary world.

\section{Literature Review}

New Zealand, similar to other nations has become enmeshed in globalisation and faced by rapid technological innovation. These factors have contributed to the introduction of an information age that has set new measures of knowledge required by a nation to remain sustainable. These changes have generated new policies, which discuss the 'knowledge society'. This notion is particularly evident in the current New Zealand context.

The literature suggests that the current Labour Government in order to respond to the needs of a changing society, since its 1999 election to power, adopted a mixture of neo-liberal and social democratic policies, commonly termed the 'Third Way'. The mastermind behind this political ideology, Anthony Gidden's, holds that the 'Third Way' is created to resolve the tension between socialism and liberalism.

Given the above, this literature review provides a brief review of the New Zealand 'Third Way' literature which discusses the 'knowledge society'. Two common themes are identified in the literature: the 'knowledge society' as embedded in 'Third Way' thinking and the 'knowledge society' as a key response to a changing society

\section{The 'Knowledge Society' is Embedded in 'Third Way' Thinking}

A key theme in the literature, generated within the "Third Way' about the knowledge society, focuses on the 'origins' of the 'Third Way'. New Zealand's political landscape, the literature suggests, has encountered two main political ideologies: socialism and neo-liberalism. The literature implies that public policy has been tampered with in an assortment of ways, from the era of the welfare state (1935-1949) that saw government intervention at its greatest - hands on approach, thought to the neo-liberal era which saw government intervention at its least - hands off approach. The literature finds the 
'Third Way' attempts to apply ideas and policies of the two ideologies in order to create a balanced policy mix. Paramount within the literature is the contextual nature of the 'Third Way'.

\section{'Third Way' Origins: Socialism and Neo-liberalism}

The concept of the 'knowledge society' is embedded in the literature within discussions of the origins of Third Way: socialism and neo-liberalism. The Third Way, Eichbaum (1999) claims, derives from the 'first' and 'second' ways. The 'first' way is found in laissez fare capitalism and the 'second' way in the socialist system. Furthermore Latham (2002) holds, that socialism and liberalism can coexist together, which string together principles of the lasting left, which concerns fairness and decency of society and applies them to contemporary issues, which Latham (2001) claims as "the massive challenges posed to social democracy by globalisation, the information revolution and the changing nature of work, welfare and social solidarity" (p. 25). Embedded in this Third Way thinking is the development of a 'knowledge society', which seeks to provide a positive response for a changing society.

\section{Third Way' origins in a New Zealand context}

'Third Way' in a New Zealand context is a refined, taylorised version of the broader 'Third Way' definition. Piercy (2003) holds that the 'Third Way' basically derived from the British set of ideas popularised by the Blair Government and Anthony Gidden's. Piercy (2003) also claims that Gidden's refers to the Third Way as "a framework of thinking and policy making that seeks to adapt socially democratic ideas to a world that has changed fundamentally over the last two to three decades" (p. 37). Closer to the primary purpose of this paper, to explore the 'knowledge society', Piercy (2003) asserts that the policies and programmes which the New Zealand Government has based around British ideas, have had to be adapted in order to fit New Zealand's unique context, which is made up of a smaller economy and specific cultural and social identities.

\section{The Contextual Nature of 'Third Way'}

The literature finds mutual ground in suggesting, that the Third Way, through the application of social democratic and neo-liberal policies seeks to create a balanced policy mix that will fit contemporary challenges that are influencing a changing society. Latham (2001) in a broader context seeks to define the modernising role of the Third Way as, "traditional principles-new circumstances-new ideas and policies" (p. 25). This modernising role is elearly apparent in the New Zealand context. The 'knowledge society' is part of a package to respond to the needs of a changing society.

\section{The 'Knowledge Society' is a Positive Response to a Changing Society}

The current government seeks to enable New Zealand to respond effectively to globalisation, technological innovation and the changing needs of society. The literature is robust with claims that a 'knowledge society' is a positive response to a changing society.

\section{Government Initiatives: A 'Knowledge Society'}

The election of the Labour Government in 1999, pinpointed the term 'knowledge' as the answer to a changing society, this would be created through greater access to education. The construction of a 'knowledge society' can be traced back through government reports. The Tertiary Education Commission (TEAC) in their first of four reports, Shaping a Shared Vision: Lifelong learning for Knowledge Society (2001a) claims, that a lot of emphasis had previously been placed on information and communications technology and the sciences and engineering. While finding this to be important the Commission holds that all forms of knowledge are important, including culture, identity, the arts and design, in developing a 'knowledge society'. The Report indicated that New Zealand does not have large industrial or technological economies, due to this the report found it particularly important that the nation focuses on 'all' forms of knowledge. This reflects Piercy's position, stated earlier in the paper, asserting that New Zealand's specific context requires re-shaping 'Third Way' principles, which includes the development of a 'knowledge society'.

\section{The Driving Forces of a Changing Society: Globalisation and Technologv}

Globalisation and technological innovation are two key factors of a changing society, which require particular kinds of knowledge. Gidden's (1999) and Latham (2001) claim these factors are key challenges which have increased interdependence across the world and transformed the way in which people live.

In New Zealand these influential factors of change are equally applicable. Globalisation and technological innovation dominate Labour government documents and reports. The 'knowledge society' is transparently embedded in reports of The Tertiary Education Commission (TEC) (2003) and the Department of Labour (DOL) (2003). These reports claim that New Zealand is faced by the challenges of globalization and technological innovation, which have revolutionised labour market dynamics. The changes forced upon society due to these challenges have increased the need for the Government to develop a 'knowledge society'.

\section{Human Capital Theory}

Abundant within the literature is the application of Human Capital Theory. Marginson (1993) provides a detailed theoretical encounter of Human Capital Theory, finding that "Human Capital Theory is the most influential economic theory of education, setting the framework of government education policies since the early 1960s" (p. 31). Blair and Schroeder, through their project and policy programme of the Third Way, assert that Human Capital theory is a primary policy objective, stating that "the most important task of modernization is to invest in human capital: to make the individual and 
business fit for the knowledge based economy of the future" (cited in Eichbaum, 1999, p.54).

The encouragement for all New Zealanders to invest in forms of higher education is evident within the Department of Labour (DOL), Ministry of Social Development (MSD) and Tertiary Education Commission (TEC) reports. Generic skills are identified as particularly important as they are transferable across a range of jobs. They claim this will ensure the protection of people's futures, and allow people to be more adaptable to change. The TEC (2003) state, "We want to encourage increased participation and learning for longer, because we believe it is the best way to help New Zealanders and the country prosper internationally"( $p$. 20). The literature indicates these three government departments work closely together towards developing strategies, programmes and policies in order to develop a 'knowledge society' in New Zealand.

\section{A Critique of the Literature}

A number of key limitations and weaknesses appeared within the review of the literature, most apparent were: the 'origins' of the 'Third Way', which leads to ambiguity of the term 'knowledge society'; the hierarchical nature of the 'knowledge society', and the gender insensitivity of the literature.

The first limitation was the grapple the literature had with the origins of the Third Way. Perched somewhere between socialism and liberalism, in a New Zealand context, social democratic and neo-liberal thinking, is the 'Third Way'. It seems somewhat to resemble a pendulum, swinging left then right, failing to achieve any real point of balance as it proposes to do in the literature. This in turn leads to a muddy understanding of the 'knowledge society' which is embedded in Third Way thinking. My aim here is not to critique the 'art' of politics, which in contemporary times resembles a pick ' $n$ ' mix of policies and a good dash of flexibility. The aim is to draw attention to 'Third Way' thinking and the strong pre-occupation the literature has with the 'left', drawing back to its socialist roots of relatively qualitative constructs. The problem with the qualitative constructs of New Zealand's 'Third Way' is the failure for the language to be specific and measurable. The qualitative language embedded in the 'Third Way', has the ability to be interpreted in a variety of ways. The 'knowledge society' is a clear example, what is knowledge? It proves to be an ambiguous concept. There are a vast range of arguments and debates forming conceptualisations of what knowledge is. The 'Third Way' needs to go beyond a pick ' $n$ ' mix of policies, and beyond the use of only qualitative language, in order to create a foundation of its own. Shifts away form the two origins: socialism and neo-liberalism to a 'Third Way' that is specific and measurable.

The second limitation, failing to be discussed in the literature was the hierarchical nature engrained in the literature. Small, yet powerful groups of 'people' are the driving force of a 'knowledge society'- political and academic officials. The main implication of this is that the majority of New Zealanders are having no say in respect to the needs of a changing society, even though they are key participants in this national experiment. Extensive generalisations have been made by the literature that a 'knowledge society' is the way forward, regardless of what the people of New Zealand, in reality think of this modernising idea.

Lastly the literature is gender insensitive. A large portion of the literature discussed issues of ethnicity and strategies to ensure ethnically disadvantaged groups can become a link in the chain of developing and strengthening skills obtained through higher education. However the literature failed to identify strategies within the tertiary education sector for moving women into higher education. This is an extremely important issue to neglect when developing a 'knowledge society', as the current government claims to build a fair and inclusive society for all New Zealanders. The future is gloomy for women and higher education if the current government fails to acknowledge women's involvement in education as an equally important issue in developing a 'knowledge society'.

\section{Summary of Review}

Perched between the pillars of social democracy ands neo-liberalism is a 'Third Way' for New Zealand. Embedded in the 'Third Way' is the 'knowledge society', the key, positive response to a changing society, brought about by the challenges of globalization and technological innovation. The literature provided a brief review of New Zealand's refined 'Third Way' and the Labour Governments, drive towards creating a 'knowledge society'. The increasing need to respond to contemporary challenges has deepened the dependence of New Zealand to invest in Human Capital. The outcomes of a knowledge society will be the protection of people's futures, the ability to adapt to change, and the enhancement of New Zealand's economy. Given the perspectives of the literature, New Zealand's future has been viewed through rose tinted lenses.

\section{Research Design}

In response to the literature above, and in light of the critique, a specific, detailed research question was formed: What are the views of management, final year, undergraduate, school leaver students about our 'knowledge society'?

This research adopted a qualitative approach in order to uncover the respondents' hidden assumptions and profound personal understanding of our 'knowledge society'. The data for this study was collected through three management students, two females and one male by means of one hour, semi structured, taped interviews. All three respondents were enrolled full-time in a BMS degree.

The research question was not asked directly of the respondents, rather a range of questions were asked, to probe into the respondents personal thoughts about knowledge and political agendas, within a New Zealand 
context. The transcribed interviews provided a foundation to work from, this allowed for the data to be reviewed a number of times. Analysis of the data involved scanning for key words and categorising the respondents' thoughts into groups. From here clear themes emerged. The analysis consisted of searching for themes parallel with the literature and themes, which provided new insights, and contradicted the literature. The themes are shared views of the three respondents. It is important to note that the respondents did not necessarily hold the same views on all subjects from this over-generalisations can not be made. Three dominant themes emerged which entail the respondents' personal insights of our 'knowledge society'.

\section{Selected Findings}

The findings are assembled into three select groups in which each entail sub-themes: "knowledge will get me the things I want", "I need current global knowledge to survive out there", and "I resent the current government".

\section{"Knowledge will Get Me the Things I Want"}

'Knowledge' was viewed by the respondents as instrumental: it held for them valuable benefits, these benefits set them aside from other groups. Three subthemes emerged from the respondents shared thoughts, which provide a unique view of what 'knowledge' means to a select group of people. The first of these benefits was knowledge will give 'me' an elite location in society. The pre-requisite for this elite location seems to derive from having a formal qualification, "If they were looking for prospective graduates now I would be likely to get the job because of my degree". This elite location entailed as sense of 'me' and 'them' (those who receive benefits and work in trade based employment). The 'me' and 'them' status had strong undertones of 'power', which became evident as the second benefit of obtaining knowledge. Power over 'them'. "I will move up the ladder faster than someone who didn't do the degree and will advance in pay brackets faster than those with tradebased jobs" and "I'm the type of person, I will go out and look for a job, and get the job I want to get, and do it to the best of my ability, whereas Jo Bloggs will go sit on the dole and be happy". A sense of knowledge = power was evident. The last valuable benefit of knowledge presented itself as success, knowledge will give 'me' a good job, security, leadership and promotions, "I just think management is a logical choice for anybody if they want to move up promotion wise". Success arose as an end result, something in which a person with a formal qualification is entitled to. The responses reflect an optimistic and individualistic view of knowledge.

\section{"I need Current Global Knowledge to Survive Out There"}

Embedded in the views of the respondents is the need to have current and global knowledge to survive in a world that has become globalised. The need to be knowledgeable of New Zealand seemed somewhat irrelevant. Knowledge did not have to be kiwi-based; global knowledge was the key to survival and 'current' knowledge of what is happening 'out there'. "A lot of management is American-we still refer back to those founding fathers of management", Westernised education is strongly associated with the respondents, "as a country we are out there with globalisation, trade access to other countries, communication wise, globalisation has only really increased because of technology". Knowledge of global issues are of importance, specifically working with different cultures, "different cultures believe different things in their work environment, so as an employer you have to be really careful with your employees and stuff". Alongside obtaining global knowledge is the strong feeling that knowledge must be current with what is happening, "In order to stay competitive we will have to stay current with what is happening globally".

The building blocks of knowledge are seen to derive from the secondary school years, and the content students are being taught is of concern to the respondents', "They do funny things at school like gardening, graphic design and home economics", This is an issue because in the eyes of the respondents, core subjects like English and mathematics are of most importance, "really we are going to get kids walking out of school with all the credits they need, really they don't know anything". This sub-theme links closely to the next theme, which illustrates the resentment of the respondents.

\section{"I Resent the Current Government"}

A form of resentment towards the government emerged within the data. This resentment drew towards the lack of incentive for people in New Zealand to work or become educated, the lack of government support for students and the strong restraints on employers. The feeling of 'them' and 'us' emerged again, "I can't see the government doing much at all". Social spending was clearly evident as an issue, "I mean look at government spending on social services, it's ridiculous, a country of over four million and over a million are on some sort of benefit. It's saying something is wrong with the system". The resentment towards the government, regarding the lack of initiatives in place for graduates seeking employment had undertones of a 'lack' of support, " I don't think they (the Government) have expectations, because if they did they would be pushing for graduates to get jobs, which I don 't see them doing, encouraging graduate recruitment". This resentment may reflect the respondents desire to work within the private sector, "I would rather go private", the direction of one respondent was, "company wise, hopefully say Fonterra, being a big international company". Again the need to be globalised can be seen as embedded in the respondents.

The separation of the respondents from the Government can be seen through the comments made; they appear to feel cheated by the government's lack of support for students and somewhat annoyed at the Government social spending. 


\section{Discussion}

The findings provided a unique insight into the minds of the respondents - a glimpse at their personal understanding of New Zealand's 'knowledge society'. Key elements emerged from the findings, which could be witnessed across all of the three themes. The findings both supported and challenged the literature.

The strong instrumentality of knowledge that emerged within the findings identified 'knowledge' as something that belongs to the individual, it gives the individual a sense of 'right' to have strong opinions without critical insight, to attack without analysis and as well as this the respondents' seemingly accepted prescribed knowledge. The question of concern here is this prescription of knowledge that perhaps fails to include critical analysis. The key elements are closely interlinked, which creates difficulty in talking of them as independent elements, below they are discussed in turn as well as in relation to one another.

There was a tendency by the respondents to have strong opinions without critical insights. The opinions were aimed at a range of areas, namely education and politics were a hot topic. All three respondents had personal opinions regarding what form of education the country should be receiving. This opinion was shared amongst all three respondents, specifically in relation to the newly introduced NCEA system in New Zealand secondary schools. These opinions were developed from the respondents' personal understanding of the system, not an analysis of literature on their behalf. Opinions on government spending were also commonly shared without any real depth of understanding of New Zealand's political landscape or societal issues. 'Third Way' was a completely new concept to the respondents' ears, the only real awareness of politics was embedded in a neo-liberal understanding of how society functions and when asked of what initiatives the government was driving forward, the respondents were silenced.

Disadvantaged groups having access to education within a 'knowledge society' were of little concern to the respondents, apparently New Zealand is a society of equality, this may be an ideal view to build opinions upon, but certainly not realistic. One does not have to search far to find evidence that a society of 'equality' is not the case. The strong opinions led to an insight, which revealed that the respondents openly attacked without analysing.

This common occurrence of the respondents, to attack without any real analysis of the situation, identified again the individualistic view embedded within their thinking. This was evident in the resentment that was felt towards the government. A naivete of the current political climate was evident, along with optimistic and individualistic attitudes, which derived from 'their' formal higher education and the prescriptive knowledge embedded within their education. Their knowledge of 'what's' currently happening out there, seemed to give them a right to have an opinion and to attack without analysis. This nature of attacking the government and those who receive benefits was common among all three respondents. It led to a final key element in the findings that the respondents accepted prescriptive knowledge. Little critical thought, which leads to critical breakdown of opinions, was applied. The knowledge required by the respondents was global and current, historical perspectives seem to have been made redundant within their minds, all that matters is what is happening here and now in order for 'me' to survive.

The findings supported the literature, in that the respondents find globalisation and technology the major driving forces of a changing society. Missing amongst the literature and findings was the concern of women and equality within the 'knowledge society', evidently it is not seen as an issue to be addressed. The findings also support the critique of the literature in that social cohesion has minimum emphasis and human capital has maximum emphasis. The findings are built upon neoliberal mindsets, in many ways human capital is of this nature. Social cohesion was not an issue discussed within the findings and barely evident within the literature.

The findings challenged the literature in a variety of ways, it was found that the respondents did not have a clear understanding of the concept of a "knowledge society', specifically in a 'Third Way' framework of thinking. An important aspect to again reiterate is that knowledge is stripped of its 'kiwi-ness'. In the minds of the respondents, knowledge does not need to be New Zealand based. The literature review found 'all' types of knowledge to be of importance, and based around New Zealand's small and specialized economy. The findings suggest this is irrelevant - the more global and current the knowledge is the better!

The respondents used the concept of knowledge as purely instrumental to them as individuals, as well as strongly associating knowledge with its market usefulness. This sense of neo-liberal mindsets provides evidence that a 'New Right/Third Way' dichotomy still exists. The literature suggests it is a balanced policy mix of neoliberalism and social democracy. The findings swing strongly toward the New Right thinking. An overall perspective could be seen in the findings, as a "knowledge society' is not to enhance society, it is to enhance the economy.

\section{Conclusion}

The 'knowledge society' is evidently a concept that can be, and will continue to be interpreted and understood in different contexts, by particular groups of people. Trying to pin-down a concrete definition of it is not possible. An interesting aspect from the findings of this paper a 'New Right/Third Way' dichotomy still exists, challenging the 'Third Way' approach of the Labour government, which claims to reside in a more Social Democratic position. New Zealand's 'knowledge society' entails knowledge of 'all' forms and aims to provide equal access to 'all' people. It is of concern that this ideal approach towards a 'knowledge society' is not embedded in the thinking of all New Zealander's, the paper clearly identifies that knowledge is seen as instrumental and self serving to 
particular groups of people. Perhaps society should celebrate the diversity of knowledge and use knowledge to empower the whole of society

\section{References}

Department of Labour. (2003). Work Trends: how work is changing in New Zealand. Wellington: Author.

Eichbaum, C. (1999). The politics and economics of the Third Way. In S Chaterjee and others. The new politics: A Third Way for New Zealand. Palmerston North: Dunmore Press.

Piercy, G. (2003). A 'Third Way' in industry training: New Zealand's adaption of selected British policies. In C. H. Jorgensen and N. Warring (Eds.), Adult Education and the Labour Market VII. Vol A, (pp. 35-62).

Latham, M. (2001). The Third Way: an outline. In A. Gidden's (Ed.). The Global Third Way Debate. (pp. 25-35). Cambridge: Polity Press.
Gidden's, A. (2001). The Global Third Way Debate. Cambridge: Polity Press.

Marginson, S. (1993). Human capital theory. In Chapter 2 in Education and Public Policy in Australia. Cambridge: Cambridge University Press.

Ministry of Social Development. (2003). Adopting a social development approach. In Statement of Attempt 2003. Wellington: Author. Available: http://www.msd.govt.nz/publications/statementof-intent-2003.html.

Tertiary Education Advisory Commission. (2001). Shaping a Shared Vision: Lifelong Learning for a Knowledge Society. Wellington: Author.

Tertiary Education Commission. (2002). A new tertiary landscape: introducing the Tertiary Education Commission. Wellington: Author. 